\title{
A TERCEIRA ONDA DO CAFÉ EM MINAS GERAIS
}

\author{
Third Wave Coffee in Minas Gerais, Brazil
}

\begin{abstract}
RESUMO
Considera-se que existam três movimentos, também denominados "ondas", influenciando o mercado e o consumo mundiais de café. Cada um apresenta um conjunto diversificado de prioridades e filosofias, contribuindo de formas diferentes para a experiência de consumo da bebida. No Brasil, a Terceira Onda ganhou força nos últimos cinco anos, o que pode contribuir significativamente para a melhoria de qualidade dos cafés consumidos no país. Objetivou-se compreender como a Terceira Onda do café se faz presente nas estratégias de cafeterias no estado de Minas Gerais, por meio de entrevistas semiestruturadas em profundidade com proprietários de três cafeterias mineiras, baseadas no conceito de Terceira Onda e localizadas em cidades de portes variados. Observou-se grande adesão destas empresas aos princípios deste movimento, mas com adoção de duas posturas distintas, de purismo e transição. Concluiu-se que tais posturas podem ser influenciadas por diversos fatores e contribuir de formas diferentes para o consumo de cafés especiais no Brasil.
\end{abstract}

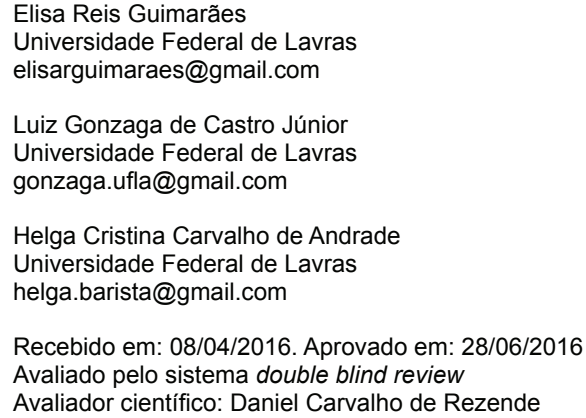

Recebido em: 08/04/2016. Aprovado em: 28/06/2016

Avaliado pelo sistema double blind review

Avaliador científico: Daniel Carvalho de Rezende

\begin{abstract}
There are three movements, also called "waves", influencing global coffee market and consumption. Each features a diversified set of priorities and philosophies, contributing in different ways for the experience in appreciating this beverage. In Brazil, the Third Wave gained momentum in the last five years, which can significantly contribute to improve the quality of coffees consumed in the country. We aimed to understand how the Third Wave Coffee presents itself in the strategies adopted by coffee shops in Minas Gerais, by means of semi-structured interviews conducted with the owners of three coffee shops located in municipalities of different sizes, based on the concept of Third Wave. We verified high adherence rate to the principles of this movement, but with the adoption of two different postures, purism and transition. We conclude that such postures may be influenced by many factors and may contribute in different ways to the consumption of specialty coffees in Brazil.
\end{abstract}

Palavras-chave: Diferenciação de Produto, Cafés Especiais, Cafeterias, Consumo.

Keywords: Product Differentiation, Specialty Coffee, Coffee Shops, Consumption.

\section{INTRODUÇÃO}

Nas últimas décadas, o mercado de café passou por significativas mudanças ligadas principalmente a novas formas de diferenciação do produto, busca por maior qualidade e novos objetivos de consumo. Tais transformações foram sintetizadas, por Skeie (2002), sob o conceito de "ondas de consumo" desta bebida. Para a autora, três movimentos, ou "ondas", com características e filosofias próprias, influenciam o mercado e o consumo mundiais de café, podendo se sobrepor ou "transbordar", influenciando o movimento seguinte.

Tal conceito evolui constantemente, mas atribui-se à Primeira Onda o aumento significativo de consumo no período pós-guerras mundiais, bem como as importantes revoluções no processamento e comercialização do produto. A Segunda Onda teria surgido como reação à baixa qualidade atribuída aos cafés do movimento anterior, sendo responsável pela introdução do conceito de cafés especiais e de origem produtora, bem como pela popularização do consumo de café espresso e do consumo da bebida em cafeterias. Por sua vez, a Terceira Onda, este o movimento mais atual, é compreendido como uma revolução no mercado de cafés especiais, marcada, dentre outros fatores, pela mudança radical de percepção do produto (agora considerado tão complexo quanto o vinho) e pela adoção de inúmeros novos fatores de diferenciação (ANDRADE et al., 2015; 
BORRELLA; MATAIX; CARRASCO-GALLEGO, 2015; GUIMARÃES, 2016).

O tempo de adoção de tais movimentos é diferente em cada país, dependendo de diversos fatores. No Brasil, a Terceira Onda ganhou força nos últimos cinco anos, o que pode contribuir significativamente para a melhoria dos cafés consumidos no país. Contudo, tal movimento ainda representa uma pequena parcela do mercado nacional e também do consumo da bebida em Minas Gerais, estado marcado por fortes tradições de consumo de café commodity (GUIMARÃES, 2016).

Objetivou-se, por meio de entrevistas semiestruturadas com proprietários de três cafeterias mineiras, representantes deste movimento, compreender como a Terceira Onda do café se faz presente nas estratégias de cafeterias no estado de Minas Gerais. Isto pode contribuir para a elaboração tanto de políticas públicas quanto de estratégias empresariais, voltadas ao aumento do público consumidor de cafés especiais, bem como à expansão deste movimento no Brasil e no estado de Minas Gerais.

\section{DIFERENCIAÇÃO DE PRODUTO E OS CAFÉS ESPECIAIS}

A diferenciação de produto é um conceito amplamente utilizado nos estudos em marketing e estratégia (SVENDSEN et al., 2011), relacionada à tomada de decisões estratégicas, voltadas à distinção de um produto de seus concorrentes, de forma a aumentar seu valor e rentabilidade (DONNET; WHEATHERSPOON; MOSS, 2010). Em geral, para serem diferenciados, basta que os consumidores percebam tais produtos como diferentes, ou seja, tenham preferências subjetivas distintas em relação a suas características físicas ou intangíveis. Em suma, a diferenciação pode ser tanto real, baseada em diferenças mensuráveis nas características do produto, quanto baseada em diferenças de percepção por parte dos consumidores, trabalhadas por meio de diversos mecanismos (NIEDERHAUSER et al., 2008; SVENDSEN, 2011).

Embora pouco exploradas nos estudos de organização industrial (SAITONE; SEXTON, 2010), a diferenciação de produto e qualidade no sistema alimentar tiveram seu interesse exacerbado pelo aumento significativo do comércio internacional de produtos agrícolas, que é estimulado pela redução de barreiras comerciais. Isso permite, por sua vez, que os consumidores tenham maior acesso a uma maior variedade de produtos diferenciados e provenientes de diversas origens (CURZI; PACCA, 2015).
No mercado de café, tem-se observado importantes mudanças relacionadas à diferenciação de produtos e melhoria de qualidade, que faz com que estes passem a ser substitutos imperfeitos e os consumidores se disponham a pagar um preço superior. Em outras palavras, a criação de atributos de diferenciação do café, tornando-os especiais, contribui para a "descommoditização" (BORRELLA; MATAIX; CARRASCO-GALLEGO, 2015; FITTER; KAPLINSKY, 2001) do produto. Tais mudanças teriam sido impulsionadas pelo aumento da demanda de cafés de qualidade, provenientes de origens específicas, a criação de novas formas de comercialização da bebida, uma maior sensibilidade quanto à sustentabilidade ambiental e aos desafios e vulnerabilidade dos cafeicultores (BORRELLA; MATAIX; CARRASCO-GALLEGO, 2015).

Neste mercado, alguns atributos de diferenciação comumente reconhecidos são a qualidade superior da bebida, o aspecto dos grãos, disponibilidade limitada (micro lotes), variedades raras, origem dos plantios, história dos cafeicultores e da propriedade na qual o café é produzido, a forma de colheita e o tipo de preparo. Consideram-se, também, aspectos relacionados à sustentabilidade ambiental, social e econômica de produção e mudanças no processo industrial, que incluem a adição ou subtração de substâncias (SAES; SOUZA; SPERS, 2001; ZYLBERSZTAJN; FARINA, 2001).

Em um dos modelos mais completos divulgados até então, Zylbersztajn e Farina (2001) destacam oito parâmetros de diferenciação do café, bem como as variáveis-chave para essa diferenciação, o tipo de bem e a principal forma de sinalização desta distinção. Para esses autores, não apenas a qualidade excepcional da bebida e seus fatores locacionais seriam importantes, mas também as qualidades socioambientais, o processo de produção, a qualidade dos serviços ofertados e do ponto de venda (PDV) do produto e os produtos comercializados de forma complementar. Seu modelo pode ser o observado na Tabela 1, a seguir.

Donnet, Weatherspoon e Hoehn (2007) sintetizaram as diferenças entre os modelos de negócios dos mercados de café commodity e especial: enquanto o mercado de café commodity teria como proposição de valor um produto homogêneo, com limitada possibilidade de melhoria e padrões de qualidade, baseados na espécie dos grãos e no país de origem, os cafés especiais seriam diferenciados por vários atributos (como origem, qualidade, variedade, entre outros). No tocante ao público consumidor, o café commodity tem como alvo um mercado padronizado e de massa, estabilizado ou declinante nas últimas décadas, enquanto os cafés especiais visariam ao consumo conspícuo e 
indulgente, direcionado a valores hedonistas, com aumento exponencial desde meados da década de 1990. Por fim, em relação à estrutura e gerenciamento da cadeia, os autores destacam o caráter concentrado do mercado de cafés commodity, com forma de obtenção a granel, sem transmissão de informação acerca da qualidade para os cafeicultores, e com torrefação em grande quantidade, de blends desqualificados. No mercado de cafés especiais, tais autores destacam uma estrutura fragmentada, com obtenção em pequenas quantidades, com comunicação mais direta entre os elos e maior transmissão de informações, bem como torrefação artesanal e com prevalência de origens únicas.

O segmento de cafés especiais surge no cenário brasileiro como uma possibilidade aos cafeicultores de conquistar compradores que estejam dispostos a pagar mais por um produto de qualidade e com característica diferenciada (OLIVEIRA; OLIVEIRA; JESUS, 2004). Na mesma linha, Pereira et al. (2010) afirmam que a diferenciação emergiu como possibilidade de desenvolver vantagens competitivas e sustentar margens de lucro mais satisfatórias ao segmento produtivo. Ademais, a atuação em mercados específicos, diferente do que ocorre no mercado das commodities, permite a negociação direta entre produtores e consumidores e um relacionamento diferenciado entre estes atores, que agora têm maior facilidade de acesso a mercados internacionais e menor relação de dependência de canais tradicionais de comercialização (PEREIRA et al., 2010; ZYLBERSZTAJN; FARINA, 2001).

Contudo, a produção de cafés especiais/diferenciados envolve uma significativa elevação nos custos de produção, relacionada a fatores destinados à melhoria de qualidade dos grãos, como mudanças nos métodos de beneficiamento e aquisição de equipamentos para despolpamento, o que pode apresentar desafio significativo para os cafeicultores brasileiros. Ademais, além de tais mudanças tecnológicas, mudanças na forma de comercialização destes produtos, a exemplo da venda em pequenos lotes, quase de forma individual, pode gerar resistência em atores acostumados à comercialização em grandes volumes (ZYLBERSZTAJN; FARINA, 2001). Por fim, ressalta-se que a baixa participação brasileira no mercado internacional de cafés especiais se deve à sua imagem de grande produtor de um único tipo de café, ao qual muitos se referem como "Tipo Santos", enquanto outros países investiram significativamente neste novo mercado (VIEIRA; CARVALHO, 2000 apud ZYLBERSZTAJN; FARINA, 2001).

No setor de torrefação, alguns desafios, que inibem o processamento de cafés especiais, são: o tamanho ainda restrito deste mercado, bem como a concorrência desleal por grandes torrefadoras (possivelmente pelos

TABELA 1 - Principais parâmetros de diferenciação do café

\begin{tabular}{|c|c|c|c|}
\hline Parâmetros & Variáveis-chave & Tipo de bem & Meios de sinalização \\
\hline $\begin{array}{l}\text { Qualidade superior da } \\
\text { bebida }\end{array}$ & $\begin{array}{l}\text { Café tipo } 3 \text { para melhor, sem defeitos, } \\
\text { bebida mole ou estritamente mole }\end{array}$ & Experiência (tangível) & Marca \\
\hline $\begin{array}{l}\text { Qualidade locacional da } \\
\text { produção }\end{array}$ & $\begin{array}{l}\text { Origem restrita (específica) ou } \\
\text { regional associada à qualidade }\end{array}$ & Crença (intangível) & Certificado de origem \\
\hline Qualidade ambiental & Menor impacto ambiental, & Crença (intangível) & Certificado de orgânico \\
\hline Qualidade social & $\begin{array}{l}\text { Mercado solidário e responsabilidade } \\
\text { social }\end{array}$ & Crença (intangível) & Certificado Fair Trade \\
\hline Processo de produção & Adição ou subtração de elementos & $\begin{array}{c}\text { Experiência (aromatizados, com } \\
\text { leite, chocolate, etc.) e Crença } \\
\text { (descafeinados) }\end{array}$ & Marca \\
\hline $\begin{array}{l}\text { Qualidade dos serviços } \\
\text { oferecidos }\end{array}$ & $\begin{array}{l}\text { Serviços adicionais (venda pela } \\
\text { internet, disponibilidade de } \\
\text { informação técnica ao consumidor) }\end{array}$ & $\begin{array}{c}\text { Pesquisa (tangível) e Experiência } \\
\text { (tangível) }\end{array}$ & Marca \\
\hline Qualidade do PDV & $\begin{array}{l}\text { Sofisticação do local de venda do } \\
\text { produto }\end{array}$ & $\begin{array}{l}\text { Pesquisa (tangível) e Experiência } \\
\text { (cafeterias, cartas de café) }\end{array}$ & $\begin{array}{l}\text { Atmosfera do PDV e } \\
\text { qualidade superior de } \\
\text { bebida }\end{array}$ \\
\hline $\begin{array}{c}\text { Produtos } \\
\text { complementares }\end{array}$ & $\begin{array}{l}\text { Produtos adicionais (xícaras, } \\
\text { máquinas de café, etc.) }\end{array}$ & $\begin{array}{c}\text { Pesquisa (tangível) e Experiência } \\
\text { (tangível) }\end{array}$ & Marca \\
\hline
\end{tabular}

Fonte: Adaptado de Zylbersztajn e Farina (2001, p. 70)

Organizações Rurais \& Agroindustriais, Lavras, v. 18, n. 3, p. 214-227, 2016 
baixos preços praticados, em função da menor qualidade da matéria-prima utilizada), a dificuldade em encontrar matéria-prima adequada e consumidores menos atentos à qualidade do produto. Contudo, algumas oportunidades são o relacionamento diferenciado com os compradores, o maior diferencial de preços e maior viabilidade de planejamento das vendas, características compartilhadas também pelos cafés orgânicos ou de origem. No varejo, especialmente em supermercados, o maior desafio é o padrão de concorrência, ainda pautado pela competição por preços baixos. No geral, problemas de coordenação entre os elos da cadeia produtiva também tendem a dificultar a maior inserção brasileira no mercado de cafés especiais, tanto em nível nacional quanto internacional (ZYLBERSZTAJN; FARINA, 2001).

Por fim, destaca-se que, para os brasileiros, o consumo de café commodity já é tradição, e que os cafés especiais, apesar de crescerem rapidamente em consumo, ainda são novidade para grande parte da população. Neste sentido, Zylbersztajn e Farina (2001) ressaltam desconhecimento destes produtos por muitos consumidores, que ainda percebem o café como produto homogêneo e, portanto, valorizam mais a competição por preço que por qualidade. Assim, ofertar qualidade ao consumidor brasileiro é tarefa difícil, também, em razão do histórico do agronegócio café, uma vez que ao mercado interno sempre restou a função de absorver os cafés que não alcançassem padrões de qualidade para exportação. Ademais, o consumidor brasileiro tem conceitos questionáveis acerca da qualidade do café, associando-a a uma bebida extraforte, tornando essenciais campanhas de esclarecimento e "educação" do consumidor (ZYLBERSZTAJN; FARINA, 2001).

\section{AS “ONDAS" DO CAFÉ}

O conceito de "ondas", para descrever a evolução do consumo de café, foi, originalmente, cunhado em 2002 pela barista Trish Skeie, em artigo intitulado "Norway and Coffee", publicado no The Flamekeeper, boletim de notícias da Roaster's Guild, aliança comercial da Associação Americana de Cafés Especiais (Specialty Coffee Association of America). Para Skeie (2002), parece haver três movimentos influenciando o mercado de café, cada um com seu próprio conjunto de prioridades e filosofias e com contribuições diferentes para a experiência de consumo. Ocasionalmente, estes movimentos ou "ondas" se sobrepõem ou "transbordam", de forma a influenciar o movimento seguinte.
A Primeira Onda, predominante no período pósguerras, estaria ligada ao aumento exponencial do consumo de café e a revoluções no processamento e comercialização do produto, até então de baixíssima qualidade. A Segunda Onda teria surgido como reação à baixa qualidade do movimento anterior, sendo responsável pela introdução do conceito de cafés especiais e de origem produtora, bem como pela popularização do consumo de café espresso e do consumo da bebida em cafeterias (ANDRADE et al., 2015; BORRELLA; MATAIX; CARRASCO-GALLEGO, 2015).

Por sua vez, o conceito de Terceira Onda, que evolui desde o seu início, diz respeito a um movimento no mercado de cafés especiais, ligado à mudança de percepção do produto, agora considerado artesanal e tão, ou mais, complexo que o vinho. Desta forma, os cafés passam a ser diferenciados por inúmeros atributos e comercializados de forma mais direta entre os elos da cadeia (ANDRADE et al., 2015; BORRELLA; MATAIX; CARRASCO-GALLEGO, 2015; GUIMARÃES, 2016). Neste sentido, Guimarães (2016) sintetizou as características da Terceira Onda do Café, dividindo-as entre seis categorias (Tabela 2).

Este conceito de "ondas" refere-se principalmente às mudanças observadas no mercado de café dos Estados Unidos da América, do Reino Unido e de alguns outros países (MANZO, 2010, 2014, 2015), devendo ser aplicado com cuidado nos demais países e regiões, uma vez que vários fatores podem influenciar o tempo e forma de adoção de cada "onda". Desta forma, ressalta-se que sua ocorrência não é uniforme entre os países: mercados mais maduros para o consumo de café já vivenciam a Terceira Onda de forma mais abrangente, enquanto, na maioria dos países produtores e/ou emergentes, nota-se a ocorrência predominante da primeira ou da segunda "ondas", com a Terceira Onda sendo observada em estágio inicial. Vale destacar, contudo, que o surgimento de uma "onda", como ressalta Skeie (2002), não causa o desaparecimento do movimento anterior: por contarem com filosofias e conjuntos de prioridades diferentes, as três ondas coexistem no mercado, alcançando segmentos de mercado e perfis de consumidores diferentes.

\section{METODOLOGIA}

Para responder à questão de "como a Terceira Onda do café se faz presente nas estratégias de cafeterias no estado de Minas Gerais", procedeu-se à realização de estudo qualitativo/exploratório. Tais estudos comumente 
envolvem o levantamento bibliográfico, entrevistas com pessoas que tiveram experiências práticas relacionadas ao problema e análise de exemplos que facilitem sua compreensão. Esta pesquisa pode, ainda, ser caracterizada como descritiva, por proceder à descrição das características de um fenômeno (GIL, 2002), neste caso, a adoção da Terceira Onda do Café em Minas Gerais.

Assim, realizaram-se, pessoalmente, três entrevistas semiestruturadas e em profundidade, com proprietários de cafeterias mineiras caracterizadas como da Terceira Onda. Os questionamentos presentes no roteiro de entrevista foram elaborados com base no trabalho e nas categorias estabelecidas por Guimarães (2016) acerca deste movimento. Informações a respeito das empresas selecionadas podem ser encontradas na Tabela 3 .
A escolha destas empresas justificou-se por seu reconhecimento no mercado nacional e entre os profissionais da área, pela capacitação de seus profissionais e proprietários; pela presença de características empresariais consoantes com o movimento estudado e por sua representatividade entre as cafeterias mineiras de Terceira Onda. Considera-se tal seleção de empresas representativa, por sua localização e tempo de atuação: uma delas está localizada em uma capital e cidade de grande porte (Empresa A, Belo Horizonte), enquanto as demais estão localizadas no interior, sendo uma em uma cidade de médio porte (Empresa B - Poços de Caldas) e a outra em uma cidade pequena (Empresa $\mathrm{C}$ - São Lourenço). Isto permite a observação de possíveis variações na adoção da Terceira

TABELA 2 - Principais abordagens acerca da Terceira Onda do Café

\begin{tabular}{|c|c|}
\hline Categoria & Temas Principais \\
\hline $\begin{array}{l}\text { Qualidade e } \\
\text { Diferenciação }\end{array}$ & $\begin{array}{l}\text { Cafés especiais, de qualidade superior; maior atenção às notas aromáticas e de sabor; preferência } \\
\text { pela espécie arábica e maior atenção aos métodos de processamento; utilização de latte art; incentivo } \\
\text { ao consumo sem aditivos; produto artesanal, preparado manualmente, complexo, sazonal, exclusivo e } \\
\text { singular; preparo em dose única; menor preocupação com a velocidade do preparo. }\end{array}$ \\
\hline $\begin{array}{c}\text { Origem e } \\
\text { Sustentabilidade }\end{array}$ & $\begin{array}{l}\text { Origem única; micro e pequenos lotes; rastreabilidade; inspiração no mercado de vinhos finos, } \\
\text { terroir e singularidade dos grãos; valorização de novas origens; Direct-Trade; empoderamento } \\
\text { do cafeicultor; sustentabilidade social, ambiental e econômica; Fair-Trade e outras certificações; } \\
\text { transparência no relacionamento com o produtor; visita à origem. }\end{array}$ \\
\hline $\begin{array}{l}\text { Torra e Métodos } \\
\text { Alternativos de Preparo }\end{array}$ & $\begin{array}{l}\text { Métodos de preparo alternativos ao espresso; venda de T\&M e coffee makers para consumo } \\
\text { doméstico; torras mais leves e recentes, em pequenas quantidades; possibilidade de torra dentro do } \\
\text { estabelecimento e sob demanda. }\end{array}$ \\
\hline $\begin{array}{l}\text { Profissionalismo } \\
\text { e Socialização do } \\
\text { Conhecimento }\end{array}$ & $\begin{array}{l}\text { Valorização e qualificação dos baristas; experimentação, cuppings, comunidades online, concursos } \\
\text { e centros de treinamento; abordagem científica dos processos; preparo como arte e ritual; } \\
\text { conhecimento aprofundado de todas as etapas da cadeia produtiva e da influência de um elo no outro; } \\
\text { parceria e maior proximidade e comunicação entre os elos; }\end{array}$ \\
\hline Consumo e Experiência & $\begin{array}{l}\text { Experiência de consumo excepcional; "educação" do consumidor; maior exigência e envolvimento } \\
\text { do cliente; maior número e aprofundamento das informações nas embalagens e cafeterias; mudança } \\
\text { no foco do serviço; criação de uma comunidade. }\end{array}$ \\
\hline $\begin{array}{l}\text { Pequenas Empresas e } \\
\text { Tecnologia de Ponta }\end{array}$ & $\begin{array}{l}\text { Micro ou pequenas torrefadoras artesanais, cafeterias independentes ou pequenas redes } \\
\text { especializadas. Máquinas manuais, em oposição à automatização da segunda onda; equipamentos top } \\
\text { de linha, altamente técnicos e especializados. }\end{array}$ \\
\hline
\end{tabular}

Fonte: Adaptado de GUIMARÃES (2016, p. 57 a 59)

TABELA 3 - Informações acerca das entrevistas realizadas

\begin{tabular}{ccc}
\hline Cafeteria & Cidade & Número de Habitantes $^{1}$ \\
\hline A & Belo Horizonte & 2.502 .557 \\
B & Poços de Caldas & 163.677 \\
C & São Lourenço & 44.781 \\
\hline
\end{tabular}

${ }^{1}$ População estimada em 2015, segundo o Instituto Brasileiro de Geografia e Estatística - IBGE (2016)

Fonte: elaboração própria

Organizações Rurais \& Agroindustriais, Lavras, v. 18, n. 3, p. 214-227, 2016 
Onda conforme o porte da cidade de localização da empresa. Ademais, as empresas $\mathrm{A}$ e $\mathrm{C}$ já têm maior tempo de atuação, tendo sido inauguradas em 2011, enquanto a Empresa B tem pouco tempo de operação, tendo sido inaugurada no segundo semestre de 2015, permitindo a observação de possíveis variações entre a atuação de cafeterias já consolidadas e aquelas recém-inauguradas no mercado.

A escolha exclusiva de cafeterias, para realização do estudo, deveu-se ao grande destaque destes atores na Terceira Onda do Café, bem como à amostra de cafeterias mineiras selecionadas, uma vez que todas elas controlam, de forma direta ou indireta, pelo menos duas das etapas de produção (plantio, torra e extração da bebida).

\section{RESULTADOS E DISCUSSÃO}

Os questionamentos realizados durante as entrevistas foram baseados no estudo de Guimarães (2016), sendo os resultados apresentados sob as mesmas categorias definidas pela autora.

\section{Qualidade e Diferenciação}

Como critérios para aquisição de seus cafés, todas as cafeterias estudadas utilizam a pontuação decorrente de metodologia da SCAA como referência para a aquisição de cafés, sendo que duas utilizam apenas grãos de pontuação acima de 84 pontos (empresas A e C), enquanto a outra utiliza grãos entre 83 e 86 pontos. Tal fato merece ser destacado, pois, apesar de todos os cafés acima de 80 pontos serem considerados especiais, classificam-se aqueles com pontuação entre 80 e 84 pontos como "muito bons", e aqueles pontuados acima de 85 como "excelentes" ou "excepcionais" (acima de 90 pontos), possuindo características altamente diferenciadas e sendo valorizados por isso (DI DONFRANCESCO; GUTIERREZ GUZMAN; CHAMBERS, 2014). Nota-se, portanto, a utilização de cafés de qualidade amplamente superior, bem como se observa a preferência por grãos da espécie arábica. Também Andrade et al. (2015), Borrella, Mataix e Carrasco-Gallego (2015) e Guimarães (2016) observaram que a utilização de cafés especiais e de alta qualidade é característica valorizada na Terceira Onda.

Também foram mencionados os critérios de adequação aos perfis de sabor e aos métodos de preparo disponibilizados pela empresa, a região de origem e a consistência de oferta, cada um desses mencionado por apenas um dos entrevistados. Vale ressaltar aqui a existência de dois posicionamentos diferenciados na aquisição do café: nas empresas A e B, as diferenças de perfil e sabor do café são aceitas e desejadas, postura característica da "Terceira Onda", enquanto na cafeteria $\mathrm{C}$ buscam-se grãos que se adequem a um dos perfis sensoriais já trabalhados pela empresa: cítrico ou frutado (podendo compor um blend, posteriormente), orgânico ou descafeinado. Neste caso, uma forma de valorizar as características únicas dos grãos é a utilização de edições limitadas, que não precisam se adequar a estes perfis ou ofertas pré-estabelecidas. Como observado por Skeie (2002), por possuírem prioridades e filosofias de consumo distintas, as “ondas" do café podem coexistir nos diversos mercados consumidores.

Destaca-se que todas as cafeterias trabalham com edições limitadas, com destaque para a empresa B que, em todos os fins de semana, em uma ação autodenominada "sábado gringo", disponibiliza um café de um país produtor diferente, com um perfil sensorial distinto daquele encontrado nos cafés brasileiros, de forma a "alimentar a biblioteca sensorial" de seus clientes. Apesar de comprarem com maior frequência de algumas fazendas fornecedoras, não têm fidelidade a nenhuma delas, mantendo-se abertas à descoberta de novos cafés a serem utilizados nas cafeterias (nunca trabalhando com o mesmo café por mais de três meses). A utilização de edições limitadas demonstra a percepção do café como produto exclusivo, singular. As edições limitadas e o interesse em despertar os consumidores para novos atributos do café também foi lembrado por Andrade et al. (2015), Borrella, Mataix e Carrasco-Gallego (2015) e Guimarães (2016) como forma de valorização e "descommoditização" do produto.

Observaram-se duas estratégias quanto à apresentação do café e postura diante da adoção de aditivos, aqui denominadas purismo e transição. Duas das cafeterias (A e B) contam com cardápio enxuto, no qual o café é o protagonista e são ressaltados seus mais variados métodos de preparo de café filtrado, com poucas bebidas à base de leite ou com algum outro aditivo, bem como com restritas opções de lanches. $\mathrm{Na}$ cafeteria $\mathrm{C}$, adota-se uma estratégia que pode ser considerada de transição entre a Segunda e Terceira Ondas: trabalha-se com inúmeros métodos diferenciados de preparo de café e disponibiliza-se grande quantidade de opções de café sem aditivos, mas também são disponibilizadas numerosas bebidas à base de café ou chocolate, chás, bebidas alcoólicas e opções para lanches. Segundo o proprietário da cafeteria, tal opção se dá pelo pouco reconhecimento e rentabilidade da Terceira Onda no país, pela predominância atual do que seria a "escola Starbucks". Como observado por Skeie (2002) e Guimarães (2016), as ondas podem coexistir em algumas 
situações. Neste caso, observa-se a simultaneidade da Segunda e Terceira Ondas não apenas no mercado como um todo, mas também nas estratégias empresariais de um mesmo negócio.

Todas as cafeterias estudadas utilizam o latte art (arte com leite vaporizado em bebidas à base de café espresso), mas a valorização e importância atribuída à técnica são encaradas de duas formas diferentes: para a empresa A, o interesse é puramente estético; para as demais, a questão é tanto estética, voltada para a agregação de valor ao produto, quanto relacionada à qualidade das matérias-primas e dos processos de produção e preparo da bebida, uma vez que o sucesso da criação do latte art depende tanto da técnica do barista (profissional do preparo da bebida) quanto da consistência da bebida e da crema do leite utilizado. A este respeito, também foi mencionado o potencial de marketing a ser explorado, por meio desta técnica, já que ela estimula os consumidores a publicarem fotos de suas bebidas e divulgarem a cafeteria em seus perfis em redes sociais, a exemplo do Facebook e Instagram.

Observou-se que, talvez pela proposta destas empresas e seu enfoque em novos métodos de preparo e em cafés de qualidade, o consumo tende a ser, em sua maioria, de café puro em duas das cafeterias estudadas ( $\mathrm{Ae} \mathrm{C}$ ), similar à característica atribuída à Terceira Onda por Guimarães (2016), sendo que o consumo de bebidas à base de café com leite é equivalente na empresa B. Contudo, isto pode indicar um maior interesse do consumidor brasileiro em novas formas do consumo de café, especialmente no caso da cafeteria $\mathrm{C}$, por sua localização em ponto turístico altamente movimentado e ampla disponibilização de opções de bebidas à base de café com variados complementos.

Notou-se que o café é preparado de forma artesanal, manualmente, sob demanda (pedido a pedido) e o mais fresco possível em todas as cafeterias estudadas. O tempo médio de atendimento varia muito, especialmente no caso de um grande número simultâneo de pedidos por cafés cujo método de preparo é mais demorado, como a French Press e o Siphon. Entretanto, estima-se um tempo máximo de 10 a 15 minutos. Observa-se, então, uma menor preocupação com a velocidade de preparo do café, sendo a qualidade da bebida privilegiada em detrimento da velocidade de atendimento. Obviamente, os entrevistados se preocupam com o tempo de atendimento, mas entendem que este tenha que ser um pouco maior, no caso dos métodos de preparo de café filtrado, amplamente valorizados em todas as cafeterias estudadas. Esse comportamento de atendimento diferenciado ao consumidor também foi descrito por Manzo (2014) quando descreveu as características da Terceira Onda.

\section{Origem e Sustentabilidade}

Constatou-se que todas as cafeterias estudadas utilizam cafés de origem única, havendo variações apenas na forma e nível de utilização. $\mathrm{Na}$ empresa $\mathrm{A}$, todos os cafés filtrados são preparados com grãos de origem única, em nível de país (no espresso, há utilização de blends). Na cafeteria $\mathrm{B}$, a origem é destacada em nível de país, origem ou fazenda e, até o momento, não há a utilização de blends. Contudo, o entrevistado destacou a intenção do uso futuro de blends para o café espresso. Por fim, na empresa C, são utilizados cafés single-origin em nível de região e fazenda, uma vez que a cafeteria opta pela utilização exclusiva de grãos da região da Mantiqueira, em Minas Gerais, onde está localizada. Destaca-se também a valorização, por estas empresas, de novas origens, demonstrada por meio da utilização de grãos "gringos", provenientes do Quênia, Etiópia, El Salvador, entre outros, pelas cafeterias A e B. A utilização de cafés de origem única e valorização de origens consideradas "exóticas", como Jamaica e Etiópia, também são características associadas à Terceira Onda por Sunderland (2012).

A importância da origem destes cafés está amplamente condicionada à qualidade dos grãos, segundo os três entrevistados. A origem estaria ligada às características únicas de cada café, decorrentes do terroir, e aos produtores, no sentido do cuidado com a produção e processo de pós-colheita dos grãos. Quanto à valorização da origem pelo consumidor, há opiniões diversas, mas tal fato parece depender, em grande parte, de seu nível de conhecimento e da aprovação da qualidade da bebida. Todas as cafeterias estudadas trabalham com micro lotes (classificação não oficial de compra de aproximadamente 50 60 sacas por fazenda) e, em alguns casos, especialmente quando da utilização de edições limitadas, nano lotes (aqui considerados até cinco sacas/lote). Também essa característica de pequenos lotes é lembrada como importante na Terceira Onda por Sunderland (2012).

Destaca-se que todas as cafeterias analisadas trabalham com o sistema de Direct-Trade, ou Comércio Direto, mesmo que com adaptações em razão das facilidades e contatos pré-existentes dos entrevistados. No caso da empresa B, muitos dos clientes são produtores e seu proprietário já conhece e tem contato frequente com muitos deles, estando inclusive ligado a uma exportadora de cafés especiais, o que facilita a adoção do sistema. A empresa $\mathrm{C}$ trabalha exclusivamente no sistema de DirectTrade, mas as visitas às fazendas se dão apenas em casos voltados à propaganda dos cafés e da região. Isto porque 0 proprietário é natural de uma importante região produtora

Organizações Rurais \& Agroindustriais, Lavras, v. 18, n. 3, p. 214-227, 2016 
de cafés especiais, de onde são adquiridos todos os cafés utilizados na cafeteria, já conhecendo e tendo contato prévio com estes produtores, que levam as amostras do café para serem aprovadas ou não. Por fim, no caso da cafeteria A, os grãos, também, são exclusivamente adquiridos por meio do Comércio Direto, mas com operacionalização diferente: a compra se dá diretamente do produtor ou por meio da cooperativa, mas o proprietário sempre visita as fazendas, pelo menos uma vez durante a safra, sendo que algumas fazendas são visitadas diversas vezes ao longo do ano. O Direct Trade é uma nova forma de comercializar cafés especiais, baseado em relacionamentos de longo prazo e em trocas diretas com os cafeicultores, de forma a alcançar a melhor qualidade possível dos grãos (LEESON, 2013; BORRELLA; MATAIX; CARRASCOGALLEGO, 2015).

Todas as cafeterias trabalham diretamente com o produtor para a melhoria dos cafés e vale ressaltar que tal ação, assim como o pagamento de um preço superior decorrente da qualidade alcançada, pode levar a seu "empoderamento", aumentando seu poder de barganha e sua base de clientes, conforme ressaltado por Borrella, Mataix e Carrasco-Gallego (2015). Este trabalho conjunto pode ter influência, também, na não adoção de certificações como critério para compra dos cafés, uma vez que os empresários estariam vendo, na prática, o que as certificadoras supostamente atestariam.

O ágio médio pago por cafés diferenciados varia muito, especialmente de acordo com a qualidade e a forma de aquisição, mas o preço pago pelos cafés especiais tende a ser muito superior àquele pago pelo café commodity, de forma a compensar todo o trabalho de preparação de lotes pequenos, retirada de defeitos e todos os demais processos para alcançar a qualidade desejada. A negociação do preço pago, nas três cafeterias, é feita diretamente entre os cafeicultores e o responsável pela compra na cafeteria, fato consistente com os estudos de Leeson (2013).

Porém constatou-se que nenhuma das cafeterias promove ações voltadas à sustentabilidade social, ambiental ou econômica da origem produtora dos cafés que utiliza. As justificativas para tanto incluem o pequeno porte do negócio e seu pouco tempo de atuação. Contudo, os entrevistados destacam ações, como empresários, que podem contribuir com tais objetivos, como adotar postura ética e coerente, cumprir prazos e compromissos, valorizar o produtor, bem como trabalhar apenas com fazendas sustentavelmente gerenciadas. O entrevistado da cafeteria B destaca, ainda, que acredita que as fazendas brasileiras, na maioria, já sejam gerenciadas para serem sustentáveis, independentemente de certificação, estando apoiadas principalmente nas leis trabalhistas e ambientais brasileiras. A não adoção de ações voltadas à sustentabilidade social, ambiental ou econômica não é consistente com o modelo proposto por Guimarães (2016). Contudo, vale lembrar que, neste trabalho, a autora buscou estabelecer um conceito global, podendo esta ser uma especificidade do cenário brasileiro, ou mesmo do estado de Minas Gerais.

O interesse dos consumidores por cafés orgânicos e de comércio justo, segundo os entrevistados, parece ainda ser incipiente no Brasil, uma vez que estes cafés são mais caros, apresentando tendência de estagnação de consumo em períodos de crise econômica. Tal fato pode ser influenciado pela tradição nacional de consumo de café commodity e a baixa parcela de cafés especiais consumida no país. Sendo assim, os consumidores brasileiros apresentam características e exigências ainda associadas à Primeira ou à Segunda Onda, nas quais tais produtos ainda não eram valorizados.

Com relação ao Fair-Trade, o entrevistado da cafeteria $\mathrm{C}$ afirma acreditar que muitos consumidores ainda não conhecem o selo e sua proposta, apesar de ele, pessoalmente, considerá-la interessante. $\mathrm{O}$ entrevistado da cafeteria A ressalta, ainda, que, apesar de quase todo o café utilizado por sua empresa ser Fair-Trade, não acredita, pessoalmente, que qualquer associação de comércio justo pague preço semelhante ao da cafeteria para os produtores. Nessa ótica, o entrevistado acredita que a certificação colabora muito no auxílio ao cafeicultor do gerenciamento de sua fazenda e de alguns processos de produção, mas "sem o cuidado devido com a qualidade do café”. Quanto ao interesse dos consumidores em visitar a origem produtora, este ainda parece ser mais acentuado entre clientes internacionais, mas todas as cafeterias estudadas já organizam ou têm planos de organizar visitas a algumas fazendas. Nota-se que no Brasil, é menor o interesse dos consumidores em visitar as demais etapas do processo produtivo, possivelmente pela proximidade das regiões produtoras, não chamando tanto a atenção quanto dos consumidores de outros países, especialmente do hemisfério norte.

\section{Torra e Métodos Alternativos de Preparo}

Nenhuma das cafeterias estudadas utiliza a torra escura, característica marcante da Segunda Onda, segundo Guimarães (2016). A preferência parece ser por torras médias, tanto por questões de qualidade relacionadas à manutenção das características únicas dos grãos quanto pela preferência dos consumidores, ainda não acostumados a torras muito suaves. A este respeito, o entrevistado da 
cafeteria $\mathrm{C}$ declara que uma torra média, mas um pouco mais escura, apesar de não ser de seu gosto pessoal e não ser o ideal em qualidade, pode funcionar como forma de adaptação para clientes que nunca consumiram cafés especiais. Este seria, assim, um passo importante na transição entre os cafés commodity extraforte comumente consumidos e os cafés especiais de torra mais clara, de qualidade superior e típicos da Terceira Onda.

Todas as cafeterias estudadas torram o próprio café, mas apenas a cafeteria A o faz dentro do próprio estabelecimento, com o torrador exposto para visualização pelos consumidores. A frequência de torra varia bastante: uma delas torra seu café diariamente, outra o faz semanalmente e, quando necessário, sob demanda, e a restante, quinzenalmente. Sendo assim, percebe-se que a torra é fresca e realizada em pequenas quantidades.

Todas as empresas estudadas dão grande enfoque e disponibilizam diversos métodos de preparo de café filtrado, com destaque para os métodos V60, French Press, Aeropress, Chemex, Kalita e Siphon. Contudo, são disponibilizados, também, o espresso e os considerados clássicos, como o cappuccino, o mocha e o machiatto. Apenas na cafeteria A, o entrevistado considerou o consumo de espresso equiparado ao de cafés filtrados, enquanto nas demais os entrevistados observam uma preferência pelos métodos filtrados. A utilização e valorização de métodos de preparo alternativos ao espresso é também característica associada à Terceira Onda por Guimarães (2016).

O preparo doméstico da bebida, por tais métodos filtrados, exige a utilização de máquinas/equipamentos, denominados coffee makers, ainda não comercializados apenas pela cafeteria B. Contudo, estes produtos já estão sendo adquiridos pela empresa, de forma cooperativa com outras cafeterias. Segundo os entrevistados das demais cafeterias estudadas, a venda destes equipamentos é altamente influenciada pelo consumo e apresentação dos cafés filtrados no estabelecimento. A partir de então, o consumidor se interessa pelos coffee makers e passa, também, a adquirir o café embalado, para o preparo doméstico ou até mesmo para presentear parentes e amigos. Essa pode ser uma adaptação interessante da Terceira Onda no Brasil, aumentando a sustentabilidade econômica dos empresários das cafeterias que, por sua vez, continuariam tendo condições de empoderar os cafeicultores.

Quanto aos formatos de café comercializados, as cafeterias A e C comercializam café verde, em pequenas quantidades, para torrefadores domésticos ou para torrefadoras/cafeterias que torram os próprios grãos. Ademais, todas as cafeterias comercializam o café torrado em grãos e disponibilizam a opção de moagem na loja, para clientes que não possuem moinhos em casa. A forma de comercialização destes cafés varia amplamente entre as cafeterias estudadas: na empresa B, eles são comercializados apenas no estabelecimento, tanto por questão de estratégia de negócio, voltada para a exclusividade dos cafés da empresa, quanto por seu porte; na cafeteria A, no próprio estabelecimento, online e em cafeterias que utilizam seus grãos, mas na forma de um blend próprio exclusivo; e na empresa $\mathrm{C}$, a comercialização é realizada no próprio estabelecimento, online e em outras cafeterias, empórios, supermercados gourmet e alguns restaurantes e hotéis. Sendo assim, destaca-se que a demanda de café torrado em grãos é altamente significativa nas empresas A e C, por trabalharem também com o fornecimento de café para outras empresas e pelo aumento recente de consumidores interessados. $\mathrm{O}$ entrevistado da cafeteria $\mathrm{B}$ afirma que, apesar do percentual de venda deste formato ainda ser pequeno em sua cafeteria, sua comercialização tem surpreendido em volume. Ele espera que, com o início da venda de coffee makers, este percentual aumente. Mais uma vez fica evidenciada a necessidade de melhoria da sustentabilidade econômica nas cafeterias de Terceira Onda no Brasil, com a adoção de estratégias de mercado alternativas à venda exclusiva de cafés nestes estabelecimentos.

\section{Profissionalismo e Socialização do Conhecimento}

Todas as cafeterias estudadas contam com baristas capacitados, treinados constantemente. Em todas elas, os baristas visitam as fazendas produtoras e pelo menos alguns deles têm conhecimento aprofundado da origem e dos processos de produção, tendo condições de informar os clientes a este respeito. Vale ressaltar que todas as cafeterias trabalham com os produtores para a melhoria dos cafés, em maior ou menor intensidade, seja fornecendo feedback sobre o aumento de qualidade de um lote ou transmitindo conhecimentos sobre aspectos relativos à produção ou procedimentos relacionados à pós-colheita dos grãos. O relacionamento com os produtores tende a ser bom, mas nem sempre fácil, especialmente pela diferença de opiniões, entre eles e os proprietários das cafeterias, acerca da qualidade do café a ser adquirido. Nestes casos, o trabalho conjunto em busca da melhoria da qualidade pode facilitar as negociações. Tais fatos são consistentes com as afirmações de Manzo (2015), que destaca a expertise acerca dos grãos, no preparo da bebida e na familiaridade com o equipamento, pelos baristas, como características essenciais da Terceira Onda do Café. 
Em apenas uma das cafeterias (empresa A), porém, alguns destes profissionais participam de concursos, podendo receber algum bônus caso vençam estes campeonatos. O proprietário desta empresa ressalta ainda os demais benefícios da participação destes profissionais em competições, que incluem a experiência e o reconhecimento em sua carreira. No caso da cafeteria B, isto ainda não acontece pelo pouco tempo de operação da cafeteria, mas o entrevistado ressalta que há interesse que estes profissionais da cafeteria participem de concursos, uma vez que isto, também, contribui como marketing positivo do estabelecimento. Por fim, apesar do incentivo do proprietário da cafeteria $\mathrm{C}$, nenhum de seus baristas participa constantemente de competições.

Quanto à liberdade dos baristas, para experimentação e criação de novos drinks ou métodos de preparo, foram obtidas três respostas bem diferentes: na empresa B, tal prática é altamente estimulada e bem-vinda, não apenas entre os baristas, mas também entre os consumidores; na cafeteria A, os baristas mais qualificados têm essa liberdade e, por vezes, criam novos drinks, mas o proprietário ressalta que eles ainda não têm tanta experiência para isso; por fim, esta prática também é aceita na empresa $\mathrm{C}$, mas com a ressalva de ser realizada no momento adequado e com parcimônia, de forma a evitar custos e desperdícios desnecessários. Todas as cafeterias trabalham com bebidas de assinatura, encontradas apenas em seu estabelecimento. Vale destacar a postura da cafeteria B, que planeja trabalhar também as bebidas de assinatura como algo sazonal, sempre as diversificando em seu cardápio.

Os padrões para extração do espresso são considerados importantes para todas as cafeterias estudadas e dois dos entrevistados (empresas A e B) declararam adotar rígidos parâmetros, a exemplo da pesagem de cada dose, enquanto o outro entrevistado acredita ser esta a postura ideal, mas admite ainda não ter este controle. Tal postura demonstra perfeccionismo e uma abordagem científica dos processos de extração, tipicamente associados à "Terceira Onda", conforme destacado por Guimarães (2016).

\section{Consumo e Experiência}

O público frequentador destas cafeterias varia bastante, especialmente pela localização diversificada das cafeterias, mas em duas delas (A e B) a maioria dos consumidores parece se situar na faixa etária de 18 a 40 anos.

Em todas as cafeterias estudadas, o café é preparado na frente do cliente e há um trabalho voltado para a "educação" do consumidor, mas ele é realizado de formas variadas. Na empresa A, isto é realizado de forma mais passiva, aguardando a demonstração de interesse pelo cliente ou a sua busca por um dos inúmeros cursos ofertados pelo estabelecimento, que incluem cursos de latte art, preparo de café coado, Q-grader e cupping da SCAA (certificação, calibragem ou retake), degustação e classificação, dentre outros. Vale ressaltar que esta empresa foi criada com o propósito de ser um centro de treinamento, aprendizado e formação técnica, só posteriormente inaugurando o espaço de cafeteria.

$\mathrm{Na}$ cafeteria $\mathrm{C}$, constatou-se a seguinte estratégia: em momentos nos quais a cafeteria está mais vazia, é estimulada uma postura mais ativa na "educação" do consumidor, de forma a encantá-lo, com o barista conversando diretamente com o consumidor e transmitindo informações acerca dos cafés utilizados. Já em horários de grande movimento, a instrução é manter o foco na operação, de forma a atender de maneira satisfatória a todos os clientes, não dando atenção demais a um e negligenciando os demais. Contudo, são adotadas estratégias indiretas que podem influenciar na "educação" do consumidor, mesmo em horários de grande movimento, como a exposição dos métodos de preparo alternativos e decorações explicativas sobre a origem e os perfis sensoriais dos cafés. Nesta cafeteria, também existe a ferramenta denominada "xicarando", na qual o cliente recebe uma bandeja autoexplicativa com quatro cafés diferentes, sendo um tradicional e três especiais, tendo a oportunidade de degustar cafés com perfis sensoriais diferentes e compreender melhor a influência da qualidade dos grãos no sabor final da bebida. Vale ressaltar, contudo, que, mesmo quando da adoção de uma postura mais ativa no processo de "educação" do consumidor, a orientação do proprietário é "ouvir mais", de forma a compreender o nível de conhecimento do consumidor para transmitir informações relevantes e compreensíveis a ele. Esta empresa também oferece cursos a seus clientes, como o de barista, de latte art e de imersão, este último para interessados em abrir cafeterias, mas que têm pouco conhecimento do negócio e do mercado. Manzo (2015) também destaca a abordagem e interlocução com os clientes como uma das principais formas de "educação" do consumidor e como característica essencial da Terceira Onda.

Por fim, observou-se que as ações de educação do consumidor na cafeteria B são mais ativas: os baristas, também sócios do negócio, procuram auxiliar o cliente na escolha do café e, a todo momento em que um café será servido, esse profissional busca falar sobre o método de extração, a qualidade e os atributos únicos daqueles grãos. Ademais, a cafeteria não disponibiliza sachês de açúcar nas 
mesas, justamente para estimular o consumidor a solicitar o produto e criar uma abertura para a explicação sobre os motivos para a não adição de açúcar à bebida. Também são expostos na cafeteria quadros explicativos sobre alguns métodos de preparo de café filtrado e, a exemplo das demais cafeterias estudadas, são ofertados cursos para os clientes. Vale ressaltar, contudo, que a "educação" do consumidor depende também de sua demonstração de interesse ou de sua liberdade na conversa com o barista, que observa e respeita caso constate a intenção/opção do cliente de consumir seu café em silêncio. Borrella, Mataix e Carrasco-Gallego (2015) ressaltam os significativos investimentos e esforços, empenhados por representantes da Terceira Onda, em ações de "educação" do consumidor.

Quanto à importância e a forma como é trabalhada a experiência de consumo na loja, o representante da empresa B destaca que o ambiente deve "caminhar na mesma direção da qualidade que vem na xícara". Sendo assim, ressalta que a qualidade deve ser apresentada, em todos os momentos, desde a apresentação da loja até a apresentação do café. Segundo o representante da cafeteria A, este aspecto é trabalhado, principalmente, com base no feedback dos consumidores. Por sua vez, o proprietário da empresa $\mathrm{C}$ destaca que o balizador da experiência de consumo na cafeteria é a compra dos cafés embalados pelo consumidor. Para ele, um aspecto interessante da cafeteria é que o "cliente paga pela degustação", ou seja, seria um ambiente em que todos estariam degustando e pagando por isso. Contudo, o ticket médio, composto principalmente pelo consumo na cafeteria, poderia ser significativamente aumentado pela compra dos cafés embalados ou métodos de preparo de café filtrado. Tais respostas, muito distintas umas das outras, são consistentes com os estudos de Manzo (2015), para quem a experiência social oferecida pelas cafeterias é influenciada por diversos fatores, dentre eles a capacidade instalada, lotação diária do estabelecimento e design interior.

As informações disponíveis nas embalagens dos cafés comercializados variaram significativamente, mas, de qualquer forma, são bem mais aprofundadas que aquelas comumente disponibilizadas por empresas de primeira e ou segunda ondas. $\mathrm{Na}$ empresa $\mathrm{A}$, são disponibilizadas informações sobre as características sensoriais dos cafés, relacionadas a sabor, acidez e retrogosto, bem como dados sobre a origem de produção, como fazenda, altitude, região de produção, informações do produtor e variedade dos grãos. Na cafeteria B, são disponibilizadas apenas informações acerca do nome da fazenda, método de processamento e variedade do café, por seus proprietários considerarem estas as informações mais importantes. Por fim, na empresa $\mathrm{C}$, esta questão é trabalhada de forma um pouco diferente: as embalagens constam com informações padrão acerca da história e premiações da empresa, mas cada café conta com uma "fita", que envolve a embalagem padrão deste café, na qual são disponibilizadas informações variáveis relacionadas à fazenda, processamento, secagem, altitude, região, informações técnicas e perfil da bebida. Tal fato é consistente com os estudos de Guimarães (2016).

Quanto ao envolvimento e exigência dos consumidores no processo de preparo, bem como seu conhecimento acerca de origens e processos, as respostas foram bem distintas. Na cafeteria B, o entrevistado ressalta o grande envolvimento e curiosidade dos clientes acerca dos métodos e processos, considerando que isso talvez possa ter alguma relação com a novidade gerada pela inauguração recente da cafeteria, mas que espera que isso não mude futuramente. $\mathrm{O}$ representante da cafeteria $\mathrm{C}$ destaca a existência de dois tipos de clientes: aqueles que só desejam tomar um bom café e aqueles realmente aficionados, "mergulhados neste processo", que fornecem feedbacks e demandam novas informações. Por fim, para o representante da cafeteria A, o consumidor final brasileiro não tem muito parâmetro para comparar qualidade, comprando o café que melhor o agrade em termos de sabor. Contudo, o entrevistado já observa um maior discernimento entre os clientes, que já aprenderam o que é café amargo ou queimado, sabendo que a bebida não deve ter estas características e deve ser saborosa, "fácil de beber". Sendo assim, destaca que diversos clientes já passam horas na cafeteria, conversando com os baristas e solicitando mais informações sobre a bebida. Tal fato pode ter influência da localização de tais cafeterias: em locais de maior movimento, especialmente em pontos turísticos, espera-se a maior frequência de consumidores de Primeira ou Segunda Onda, enquanto nas demais localidades, também pela maior dificuldade de acesso, espera-se maior afluência de consumidores engajados, aficionados. A coexistência das "ondas" do café, conforme mencionado por Skeie (2002), também explica esse fenômeno.

Ambas as cafeterias A e C já fazem sessões de degustação com seus clientes, especialmente com café coado. Na empresa A, busca-se seguir a metodologia de prova do cupping oficial, diferenciando-se apenas no número de xícaras e pela não utilização de formulários, de forma que mais clientes possam participar do evento. $\mathrm{Na}$ empresa $\mathrm{C}$, busca-se aproximar o preparo ao máximo do que seria realizado na casa do cliente, de forma a aproximar a experiência de sua realidade. Na cafeteria B, já está

Organizações Rurais \& Agroindustriais, Lavras, v. 18, n. 3, p. 214-227, 2016 
prevista a realização de cuppings, mais aproximados do modelo profissional, de forma a demonstrar aos clientes como o processo funciona. Pretende-se, no entanto, adotar uma postura mais leve, sem tanta seriedade, de forma que os clientes também se sintam à vontade para experimentar o café da forma que desejarem. Holmberg (2011) lembra que a prática do cupping oferece aos consumidores uma oportunidade de explorar e comparar características de cafés provenientes de diferentes regiões produtoras. Esta técnica é, também, atribuída, pela autora, à Terceira Onda do Café, que prega a valorização dos atributos únicos dos cafés especiais.

Quanto à existência de clubes ou confrarias de café nas cidades onde estão localizadas as cafeterias estudadas, foi observada a existência em Belo Horizonte e Poços de Caldas e, em ambos os casos, alguns de seus clientes frequentam esses ambientes, seja de forma online ou presencial. Vale ressaltar, porém, o interesse do entrevistado da empresa B em criar uma confraria própria da cafeteria, de forma a incentivar ainda mais a busca do conhecimento acerca da qualidade dos cafés por parte de seus clientes. Tais ações são direcionadas à educação do consumidor e à criação de uma comunidade em torno do consumo de cafés especiais. A tentativa de reconectar produtores e consumidores, além de criar uma comunidade em torno da bebida, é também destacada por Edwards et al. (2013).

\section{Pequenas Empresas e Tecnologia de Ponta}

Todas as cafeterias estudadas possuem apenas uma loja, fato consistente com os estudos de Manzo (2010), que ressalta como representantes deste movimento pequenas torrefadoras artesanais e cafeterias independentes ou pequenas redes. Todas elas controlam o processo de torra e todos os procedimentos da cafeteria. Ambas as cafeterias A e C têm grande controle sobre a maioria dos cafés utilizados em seus estabelecimentos, por estas fazendas serem de propriedade de suas famílias. Contudo, ressalta-se que, em virtude da adoção do Direct-Trade e do trabalho conjunto com os produtores, em busca da melhoria da qualidade dos cafés, todas as cafeterias têm grande conhecimento e certo controle sobre os demais cafés utilizados.

Apenas a cafeteria B trabalha exclusivamente com clientes pessoa física, comercializando um volume médio de 45 50 kg mês, enquanto as demais também trabalham no modelo business to business (também fornecem café para outras empresas/cafeterias), apresentando volume médio de vendas em torno de 400 450 kg café/mês. As empresas A e B operam em espaços pequenos, abaixo de $50 \mathrm{~m}^{2}$, ambas tendo capacidade instalada para atendimento de cerca de 40 clientes por vez e contando com cinco e seis funcionários (todos baristas), respectivamente. Salienta-se que esta é a área estimada da parte de cafeteria da empresa A localizada em um terreno grande, com espaço específico destinado à torra, aos cursos e treinamentos. Por sua vez, a cafeteria $\mathrm{C}$ conta com oito funcionários, dos quais quatro são baristas, $150 \mathrm{~m}^{2}$ de espaço interno e capacidade instalada para atendimento de 60 clientes por vez. Tal fato é consistente com os estudos de Rosemblum (2015), que destaca a tendência, dentre os representantes da Terceira Onda, de começar a vender seus cafés embalados também em outros canais tradicionais de varejo, além de seus próprios estabelecimentos.

Enfatiza-se que, quando questionados sobre seus principais concorrentes, dois dos entrevistados citaram apenas concorrentes indiretos, por não haver concorrentes diretos e com o mesmo tipo de proposta na cidade da cafeteria entrevistada (empresa B) e ou por não acreditarem em fidelidade a marcas no mercado de cafés especiais, considerando maiores ameaças as empresas que trabalham com cafés intermediários com grande poder econômico de barganha (empresa C). O entrevistado da cafeteria A ressaltou concorrentes diretos, mas todos em nível nacional, não tendo nenhum representante com a mesma proposta de trabalho na cidade de Belo Horizonte. Sendo assim, o mercado nacional parece ser grande o suficiente para as empresas existentes focadas em cafés especiais, não havendo grande concorrência entre elas e, inclusive, podendo ser observado certo senso de colaboração entre as empresas. Isto mostra como o nicho de cafés especiais, particularmente daqueles de Terceira Onda, ainda é pouco explorado em Minas Gerais e no Brasil.

Quanto às máquinas utilizadas para o preparo de espresso, destaca-se o equipamento comprado, das marcas La Marzocco e Nuova Simonelli (antiga e atual patrocinadoras do campeonato mundial de barismo, respectivamente), todas semiautomáticas de dois grupos, com variações apenas nos modelos. Vale ressaltar que, mesmo com a utilização de máquinas semiautomáticas, nas quais algumas configurações já vêm de fábrica (como a pressão da água) o barista tem grande influência no preparo, em aspectos como o tempo de extração, a quantidade de gramas utilizados, dentre outros.

\section{CONCLUSÕES}

Vale ressaltar o interesse prático desta pesquisa, que pode ser útil na elaboração tanto de políticas públicas quanto de estratégias empresariais, voltadas ao aumento 
do público consumidor de cafés especiais, bem como à expansão deste movimento no Brasil e no estado de Minas Gerais. A Terceira Onda parece ter grande potencial de expansão no país, uma vez que este mercado ainda é muito restrito, tendo se desenvolvido com maior intensidade nos últimos cinco anos. Este potencial não é ilimitado, mas ainda assim pode contribuir, significativamente, com a qualificação do consumo de café no Brasil, benéfico para todos os elos da cadeia.

Quanto à adoção da Terceira Onda pelas três cafeterias mineiras estudadas, pôde-se observar grande semelhança com o conceito e as categorias definidas por Guimarães (2016). Contudo, notam-se diferentes níveis de aplicação dos preceitos da Terceira Onda, levando à definição de duas posturas/estratégias distintas: uma tipicamente de transição entre Segunda e Terceira Ondas e uma mais purista. Enquanto na postura considerada purista, aqui atribuída às cafeterias $\mathrm{A} e \mathrm{~B}$, os preceitos da Terceira Onda são adotados de forma quase idêntica ao modelo mais tradicional, na postura de transição são observadas "concessões" de forma a auxiliar o consumidor no processo de mudança entre o consumo de cafés tradicionais e cafés especiais. Tais "concessões" seriam: o uso não de torras escuras, mas de uma coloração média/escura, de forma a reduzir o estranhamento do consumidor ao mudar do consumo de cafés tradicionais para cafés especiais; o trabalho com um cardápio mais extenso, disponibilizando todos os métodos de café filtrado, mas também opções de drinks/bebidas à base de café com leite (também com maior quantidade de complementos) e maior opção de lanches e o trabalho com um número limitado de perfis de sabor, aos quais os cafés adquiridos devem se adequar, fato contrabalançado pela oferta de edições limitadas, que atenderiam, também, ao interesse por notas e sabores diferenciados por parte de clientes mais engajados na Terceira Onda.

As cafeterias estudadas podem ser consideradas representativas do universo de pesquisa, uma vez que essa "onda" ainda é muito recente em nível estadual, tendo se desenvolvido principalmente nos últimos cinco anos, havendo poucas destas empresas no estado de Minas Gerais. Mas, em trabalhos posteriores, propõe-se o estudo com uma amostra maior de cafeterias, também em outros estados da federação, de forma a comparar suas estratégias e níveis de adoção da Terceira Onda, estabelecendo possíveis fatores de influência na expansão do movimento e contribuindo com a discussão acerca do tema.

Vale lembrar que todas essas cafeterias controlam, de forma direta (realizada pela própria empresa) ou indireta (Direct-Trade ou empresa separada, mas de controle familiar), pelo menos duas das etapas de produção (plantio, torra e extração da bebida). Sendo assim, é válido o estudo com outros atores desta cadeia, que controlem apenas uma destas etapas, de forma a identificar potenciais desafios ou oportunidades na coordenação dessas atividades.

Propõe-se um estudo aprofundado das categorias e temas identificados e associados à Terceira Onda do Café, aqui apresentados. Incentiva-se, também, o aprofundamento em estudos destinados a estabelecer quais fatores estimulam a adoção das estratégias de purismo ou transição pelas cafeterias de Terceira Onda, conhecimento com grande potencial de contribuição para esse segmento de mercado.

\section{AGRADECIMENTOS}

Agradecemos à Coordenação de Aperfeiçoamento de Pessoal de Nível Superior (CAPES) pelo apoio financeiro e à Universidade Federal de Lavras (UFLA) pelo apoio técnico e didático.

\section{REFERÊNCIAS}

ANDRADE, H. C. C. et al. Atribuição de sentidos e agregação de valor: insumos para o turismo rural em regiões cafeicultoras. Revista Brasileira de Ecoturismo, São Paulo, v. 8, n. 2, p. 333-346, 2015

BORRELLA, I.; MATAIX, C.; CARRASCO-GALLEGO, R. Smallholder farmers in the speciality coffee industry: opportunities, constraints and the businesses that are making it possible. IDS Bulletin, Brighton, v. 46, n. 3, p. 29-44, 2015.

CURZI, D.; PACCA, L. Price, quality and trade costs in the food sector. Food Policy, Guildford, v. 55, p. 147-158, Aug. 2015.

DI DONFRANCESCO, B.; GUTIERREZ GUZMAN, N.; CHAMBERS, E. Comparison of results from cupping and descriptive sensory analysis of Colombian brewed coffee. Journal of Sensory Studies, v. 29, n. 4, p. 301311, Aug. 2014.

DONNET, M. L.; WEATHERSPOON, D. D.; HOEHN, J. What adds value in specialty coffee?: managerial implications from hedonic price analysis of Central and South American e-auctions. International Food and Agribusiness Management Review, New York, v. 10, n. 3, p. 1-18, 2007.

Organizações Rurais \& Agroindustriais, Lavras, v. 18, n. 3, p. 214-227, 2016 
DONNET, M. L.; WEATHERSPOON, D. D.; MOSS, C. B. Measuring food product differentiation by quality ratings: a cross-entropy analysis of specialty coffee e-auctions. Journal of Agricultural Economics, Malden, v. 61, n. 1, p. 122-137, 2010.

EDWARDS, E. et al. Collective spaces and collected action: towards reconnecting food, consumers and nature. In: ACM conference on Pervasive and ubiquitous computing adjunct publication, 2013, Zurich. Proceedings... Zurich: ACM, 2013. p. 563-570.

FITTER, R.; KAPLINSKY, R. Who gains from product rents as the coffee market becomes more differentiated?: a value-chain analysis. IDS Bulletin, Brighton, v. 32, n. 3, p. 69-82, 2001.

GIL, A. C. Como elaborar projetos de pesquisa. São Paulo: Atlas, 2002. 175 p.

Guimarães, E. R. Terceira Onda do Café: Base Conceitual e Aplicações. 2016. 135 p. Dissertação (Mestrado em Administração). Universidade Federal de Lavras.

HOLMBERG, S. R. Solving the 'coffee paradox': understanding Ethiopia's coffee cooperatives through Elinor Ostrom's Theory of the Commons. 2011. 173 p. Thesis (Ph.D. in Philosophy) - University of Massachusetts, Amherst, 2011.

INSTITUTO BRASILEIRO DE GEOGRAFIA E ESTATÍSTICA. IBGE cidades: Minas Gerais. Disponível em: <http://www.cidades.ibge.gov.br/xtras/uf.php?lang=\& coduf $=31 \&$ search $=$ minas-gerais $>$. Acesso em: 7 fev. 2016 .

LEESON, M. Burundi in the World of Direct Trade and Specialty Coffee. 2013. 113 p. Dissertação (Mestrado em Filosofia). University of Oslo, Oslo.

MANZO, J. Coffee, connoisseurship, and an ethnomethodologically-informed sociology of taste. Human Studies, Dordrecht, v. 33, n. 2/3, p. 141-155, 2010.

MANZO, J. Machines, people, and social interaction in "Third-Wave" coffeehouses. Journal of Arts and Humanities, Rockville, v. 3, n. 8, p. 1-12, 2014.
MANZO, J. "Third-Wave" coffeehouses as venues for sociality: on encounters between employees and customers. The Qualitative Report, Fort Lauderdale, v. 20, n. 6, p. 746-761, 2015.

NIEDERHAUSER, N. et al. Information and its management for differentiation of agricultural products: the example of specialty coffee. Computers and Electronics in Agriculture, New York, v. 61, n. 2, p. 241-253, 2008.

OLIVEIRA, J. L. R.; OLIVEIRA, S. L.; JESUS, J. C. S. Análise de fatores mercadológicos para a formação de preço do café especial. In: SEMINÁRIOS EM ADMINISTRAÇÃO, 7., 2004, São Paulo. Anais... São Paulo: FEAUSP, 2004. 1 CD-ROM.

PEREIRA, V. F. et al. Riscos e retornos da cafeicultura em Minas Gerais: uma análise de custos e diferenciação. Revista de Economia e Sociologia Rural, Brasília, v. 48, n. 3, p. 657-678, 2010.

SAES, M. S. M.; SOUZA, M. C. M.; SPERS, E. E. Diagnóstico sobre o sistema agroindustrial de cafés especiais e qualidade superior do estado de Minas Gerais. São Paulo: SEBRAE, 2001. 152 p.

SAITONE, T. L.; SEXTON, R. J. Product differentiation and quality in food markets: industrial organization implications. Annual Review of Resource Economics, Palo Alto, v. 2, n. 1, p. 341-368, 2010.

SKEIE, T. Norway and coffee. 2002. Disponível em: $<$ https://timwendelboe.no/uploads/the-flamekeeper-2003. pdf $>$. Acesso em: 30 abr. 2015.

SUNDERLAND, S. Trading the happy object: coffee, colonialism, and friendly feeling. M/C Journal, Kelvin Grove, v. 15, n. 2, p. 1-9, 2012.

SVENDSEN, M. F. et al. Marketing strategy and customer involvement in product development. European Journal of Marketing, Bradford, v. 45, n. 4, p. 513-530, 2011.

ZYLBERSZTAJN, D.; FARINA, E. M. M. Q. Diagnóstico sobre o sistema agroindustrial de cafés especiais e qualidade superior do Estado de Minas Gerais: relatório final PENSA/FEA/USP. São Paulo: USP, 2001. 152 p. 